\title{
Ocular Complications among Cases of Head Injury Seen in a Neurosurgical Hospital in Southeastern Nigeria
}

${ }^{1}$ O Okoye MввS; FNMC, NO Magulike мввS;FRCS;FW ACS, CM Chuka-Okosa MBвS;MSc;FWACS

Department of Ophthalmology, University of Nigeria Teaching Hospital, Enugu, Nigeria

\section{Abstract}

Background: Head injuries with ocular involvement are of great importance due to the visual morbidity and mortality which may result.

Objective: To determine the pattern of ocular complications among cases of head injury seen in Memphys Hospital for Neurosurgery, Enugu, in south-eastern Nigeria.

Patients and Methods: In a prospective study, consecutive patients with head injury seen in Memphys Hospital for Neurosurgery, Enugu, from June 2007 to May 2008 were analysed for age, sex, cause of head injury, presence or absence of ocular complication and type of ocular complication.

Results: A total of 26 patients were analysed -21 men and 5 women ( $M: F=4: 1$ ), with an age range from 21-64 years.

Road traffic accident was the leading cause of head injury, accounting for $88.3 \%$ of all the cases. All the patients presented within 72 hours of injury.

Fifteen $(57.7 \%)$ of the 26 patients had ocular complications in one or both eyes. The complications were more neuro-ophthalmic (76.2\%) than ophthalmic (23.8\%).

Damage to the ocular cranial nerve was the most frequently occurring injury, accounting for $61.9 \%$ of all complications, followed by soft tissue injury, which was seen in $5(23.8 \%)$ cases.

Conclusion: Neuro-ophthalmic complications involving the ocular cranial nerves were the most commonly occurring complication among the cases of head injury seen in Memphys Hospital for Neurosurgery, Enugu.

Key words: Ocular complications, head injury, Nigeria

\section{INTRODUCTION}

Road traffic accidents have been on the increase in Nigeria. Some studies ${ }^{1-3}$ have attributed this increase to poor road infrastructure, non-adherence to traffic rules and regulations by road users, and the increasing use of motorbikes as a means of transportation. Head injuries with multiple facial, ocular and neuro-ophthalmic involvement are a common outcome of these accidents. ${ }^{4-8}$ They are of great significance due to the visual morbidity and mortality that could result. Even though direct injury to the orbit and globe can easily result in ophthalmic disorders, it is less appreciated that distant head injury can similarly result in injury to the retrobulbar afferent visual pathways. ${ }^{4}$

Reports from various studies show that the prevalence of ocular complications among head injuries range from $83.5 \%$ in Kulkarn et al.'s cohort; ${ }^{8} 40 \%{ }^{7}$ in Magulike (southeastern Nigeria) $)^{5}$ to $25.3 \%$ in Odebode's study ${ }^{5}$ in llorin, Kwara State, Nigeria.

While Odebode et al. ${ }^{5}$ in their study in llorin, western Nigeria found that soft tissue injury to the globe and adnexa were the most common complication of head injuries, Magulike $\mathrm{e}^{7}$ reported neuro-ophthalmological complications as the most common in his cohort. These retrospective studies were, however, carried out in multidisciplinary tertiary hospitals.

This prospective study was carried out in a hospital in southeastern Nigeria which is exclusively for neurosurgical patients.

The aim of the study is to determine the spectrum of ocular complications seen among cases of head injury seen in an exclusively neurosurgical hospital.

\section{PATIENTS AND METHODS}

A prospective study of all the cases of head injury with ocular complications seen in Memfys Hospital for Neurosurgery, Enugu, southeastern Nigeria, from June 2007 to May 2008 was undertaken. All new cases of head injury presenting to the hospital for the first time were included in the study.

All the patients except those with altered level of consciousness were administered a questionnaire by a resident doctor. An informant filled the questionnaire for those patients with altered level of consciousness. There were three sections in the questionnaire. Section A sought information on the patient's biodata; Section B dealt with the patient's medical history and Section $C$ covered findings on systemic and ocular examination The findings in section $C$ were further confirmed by the consultant neurosurgeon and ophthalmologist. All patients had ancillary investigations in addition to computed tomographic scan of the head. 


\section{RESULTS}

There were $21(80.8 \%)$ male patients and 5 (19.2\%) female patients, with a male to female ratio of $4: 1$. The age range of the patients was 1-60 years, however, those in the $21-40$ years age group accounted for $61.5 \%$ of cases. Only 2 patients each were in age ranges 1-20 and 41-60, respectively, as shown in table 1.

Road traffic accident was the cause of head injury in 23 $(88.3 \%)$ patients. However, assault, fall from a height and gunshot injury accounted for $1(3.9 \%)$ patient each. All the patients presented within 72 hours of injury.

Of the 26 cases of head injury seen, $15(57.7 \%)$ patients had ocular complications, with 21 eyes affected. A total of 9 $(60 \%)$ patients presented with unilateral complications, while $6(40 \%)$ had bilateral involvement of the eyes. Multiple ocular involvement was seen in $5(33.3 \%)$ patients.

Ocular cranial nerve injury (involving the facial, oculomotor, abducent or the optic nerve) was the most commonly occurring ocular complication followed by soft tissue injury of the lid and adnexa, accounting for $61.9 \%$ and $23.8 \%$ of the complications, respectively. Disc oedema was seen in $3(14.3 \%)$ eyes(see table 3$)$.

Table 1. Age/sex distribution of 26 patients with head injuries

\begin{tabular}{lcrrr}
\hline Age & Female & Male & Total & $\%$ \\
\hline $1-20$ & - & 2 & 2 & 7.7 \\
$21-40$ & 4 & 12 & 16 & 61.5 \\
$41-60$ & - & 2 & 2 & 7.7 \\
$>60$ & 1 & 5 & 6 & 23.1 \\
\hline TOTAL & 5 & 21 & 26 & 100 \\
\hline
\end{tabular}

Table 2. Causes of head injury

\begin{tabular}{lcc}
\hline Activity & No of patients & Percentage (\%) \\
\hline RTA & 23 & 88.5 \\
Assault & 1 & 3.8 \\
Fall from height & 1 & 3.8 \\
Gun shot injury & 1 & 3.8 \\
\hline TOTAL & 26 & 100 \\
\hline
\end{tabular}

Table 3. Ocular complications seen in 21 eyes of the 15 patients

\begin{tabular}{lcl}
\hline Type of injury & No. of eyes & $\%$ \\
\hline Lid laceration/oedema & 3 & 14.3 \\
Chemosis/subconjuctival haemorrhage & 2 & 9.5 \\
Ocular cranial nerves injury & 13 & 61.9 \\
Disc oedema & 3 & 14.3 \\
\hline TOTAL & 21 & 100 \\
\hline
\end{tabular}

\section{DISCUSSION}

Head injuries with ocular complications are of great importance due to the morbidity and visual loss, which may result.
In this study we analysed the records of all patients with head injuries who presented to Memphys Hospital for Neurosurgery, Enugu, South-Eastern Nigeria over a oneyear period (June 2007- May 2008).

\section{Sex}

The preponderance of male patients is similar to the findings in other studies. ${ }^{5,7,8}$ This is probably due to the fact that men are more likely to be involved in activities that could lead to injuries, such as assault, or a fall from a height, etc.

\section{Age}

Most of the patients (61.5\%) were aged 21-40 which is similar to the findings in other studies. ${ }^{5,7,8}$ This is to be expected as this age range constitutes the predominant active age group, which is more vulnerable to injuries.

\section{Cause of head injury}

In this study, $23(88.3 \%)$ of the 26 patients had head injury as a result of road traffic accidents (RTA). An earlier study ${ }^{7}$ in Enugu showed RTA as the most common aetiological factor accounting for $63 \%$ of cases of head injury. Similarly, RTA accounted for $52.50 \%$ of the cases of head injury seen in the study by Kulkarni et al. ${ }^{8}$ However, the high percentage for RTAs in the present study $(88.5 \%)$ is similar to the finding by Odebode et al. ${ }^{5}(84.2 \%)$ in Ilorin, Kwara State, (western Nigeria).

The high percentage for RTAs seen in this study could be attributed to the increasing use of motorbike as a means of intracity transportation at the time of this study. ${ }^{1-2}$ Most motorbike drivers/riders do not use helmets and thus are vulnerable to injuries to the head in case of accidents. ${ }^{1-2}$ Of the 15 cases of head injury presenting with ocular complications, RTAs accounted for 12 (87\%). Of these, motorbike-related accidents accounted for 8 (66.7\%).

\section{Time of injury}

In the cohort in this study, all the patients presented within 72 hours of injury. This is largely because this hospital is the only well equipped neurosurgical hospital in southeastern Nigeria. Other studies ${ }^{4,8}$ did not indicate time of presentation.

\section{Prevalence of ocular complications}

Ocular involvement was found in 15 (57.7\%) out of the 26 cases of head injuries in the cohort.

When compared to other studies, ocular complications in head injury cases accounted for $25.3 \%$ in Oyebode 5 ; $40 \%$ in Magulike ${ }^{7}$ and $85.50 \%$ in Kalkarni. ${ }^{8}$ The variation in the figures observed in the studies could be accounted for by factors such as type of study, sample size and type of hospital. While this study examined 26 consecutively seen head-injury cases in an exclusively neurosurgical hospital, Magulike $^{7}$ retrospectively studied 100 cases admitted at 
different times in the neurosurgical ward of a multidisciplinary hospital. Odebode et al. ${ }^{5}$ and Kulkarni et al. ${ }^{8}$ prospectively studied 225 and 200 head injury patients respectively, on admission at the neurosurgical wards of multidisciplinary teaching hospitals.

\section{Types of ocular complications}

Generally, more neuroophthalmic (72\%) than ophthalmic complications were encountered in this study. This is contrary to the findings from other studies ${ }^{5,7}$ in which both neuroophthalmic and soft tissue injury to the globe and adnexae were almost equally seen (50 and $49 \%$ respectively).

This change in pattern could be attributed to the fact that this study was carried out in a strictly neurosurgical centre which also serves as a major referral centre for the more severe head injuries.

Neuroophthalmic involvement in head injury is a well known pointer to the degree and severity of injury. ${ }^{8}$ In the Kulkarni et al. ${ }^{8}$ cohort, all 21 patients who died following head injury had neuroophthalmological complications.

In addition, the sample sizes in the other studies ${ }^{5,7}$ were 4 to 8 times larger than the size in this study, which consisted of just 26 cases.

Of the neuroophthalmological complications encountered in the present study, cranial nerve palsies $\left(2^{\text {nd }}, 3^{\text {rd }}, 6^{\text {th }}\right.$ and $\left.7^{\text {th }}\right)$ occurred in $13(61.9 \%)$ eyes. However, in the Odebode et al. ${ }^{5}$ and Kulkarni et al. series, cranial nerve involvement accounted for $49 \%{ }^{5}$ and $2.5 \%$ of ocular complications respectively.

While disc oedema accounted for $13.3 \%$ of the ocular complications seen in this series, it was seen in only $5.5 \%$ of cases in Kulkarni et al.' $\mathrm{s}^{8}$ cohort and not at all in Odebode et $\mathrm{al}^{\prime} \mathrm{s}^{5}$ study.

Cases of orbital fractures which were reported in Odebode et al. ${ }^{5}$ and Kulkarni et al. ${ }^{8}$ were not found in the present study. Additionally, cases of facial nerve palsy were seen in this study, which did not occur in the Kulkarni ${ }^{8}$ or Odebode series.

The limitations of this study included the small sample size. Its major strength, however, was that it was a prospective study.

\section{CONCLUSION}

The results of this study suggest that neuroophthalmic complications involving the cranial nerves are now the most common ocular complication among head-injury cases seen in a neurosurgical centre in southeastern Nigeria. This is followed by soft tissue injury to the globe and adnexa. It is recommended that in a larger study, interventional measures as well as visual morbidity and mortality be determined as well at the time of presentation and on follow up.

\section{ACKNOWLEDGEMENT}

We wish to thank the medical director of Memfys Hospital of Neurosurgery, Enugu, Professor SC Ohaegbulam for his kind permission to carry out this study in his hospital.

\section{REFERENCES}

1. Afamdi ZO. Trends and characteristics of road traffic accidents in Nigeria. Journal of the Royal Society for the Promotion of Health 2007; 106(1): 27-9

2. Editorial: Road Traffic Accidents in Nigeria. Heal Nigeria April 2009

3. Asogwa SE. Road traffic accident in Nigeria: a review and a reappraisal. Accid Anal Prev. 1992; 24(2): 149-55

4. Levin LA. Neuroophthalmologic diagnosis and therapy of central nervous system trauma. Ophthalmol Clin North Am. 2004; 17(3): 455-64.

5. Odebode TO, Ademola-Popoola DS, Ojo TA, Ayanniyi AA. Ocular and visual complications of head injury. Eye. 2005; 19(5): 561-6.

6. Shokunbi T, Agbeja A. Ocular complications of head injury in children. Childs Nerv Syst 1991; 7(3): 147-9.

7. Magulike NO. Ophthalmic manifestation of head and facial injuries. Nig J Surg Sciences 2000; 10: 1-3.

8. Kulkarni AR, Aggarwal SP, Deshpande MD,Walimbe PB, Labhsetwar AS. Ocular manifestations of head injury: a clinical study. Eye. 2005; 19(12): 1257-63 